\title{
Spot Sale of Uncommitted LNG from Middle East: Japan or the UK?
}

\author{
Dr Hamed Nikhalat-Jahromi (Corresponding Author) \\ Affiliation (1): Management Consultant in Oil \& Gas Industry \\ Address: No. 1303, Al-Owais Tower, Deira, Dubai, United Arab Emirates; P.O.BOX: 61820 \\ Affiliation (2): INESC Porto L.A. \\ Address: Rua Dr. Roberto Frias, 4200 Porto, Portugal \\ Tel.: +97142259292 \\ Emai: hnj08@alumni.imperial.ac.uk
}

\begin{abstract}
Prof Michael G. H. Bell
Affiliation: Institute of Transport and Logistics, University of Sydney

Address: Room 311, C37 - Newtown Campus, The University of Sydney, NSW 2006 Australia Email: michael.bell@sydney.edu.au
\end{abstract}

\author{
Prof Dalila B.M.M. Fontes \\ Affiliation (1): INESC Porto L.A. \\ Address: Rua Dr. Roberto Frias, 4200 Porto, Portugal \\ Affiliation (2): Faculdade de Economia, Universidade do Porto \\ Address: Rua Dr. Roberto Frias, 4200 Porto, Portugal \\ Affiliation (3): Department of Industrial and Systems Engineering, Texas A\&M University \\ Address: College Station, TX 77840, United States \\ Email: fontes@fep.up.pt
}

Prof Robert A. Cochrane

Affiliation: Port Operations Research and Technology Centre (PORTeC), Imperial College London Address: Room 337, Skempton Building, South Kensington Campus, Imperial College London,

SW7 2BU, United Kingdom

Email: robert.a.cochrane@btinternet.com

Dr Panagiotis Angeloudis

Affiliation: Port Operations Research and Technology Centre (PORTeC), Imperial College London Address: Room 337, Skempton Building, South Kensington Campus, Imperial College London,

SW7 2BU, United Kingdom

Email: p.angeloudis@imperial.ac.uk 


\section{Spot Sale of Uncommitted LNG from Middle East: Japan or the UK?}

Abstract: the importance of liquefied natural gas (LNG) is rising as demand for it grows rapidly and steadily due to growth in energy demand, the transition to a low carbon economy and the longer distances over which natural gas is now traded. Given its importance, this work proposes an optimization model that assists to decide on when and where LNG should be delivered by coordinating tanker type, assignment and routing, inventory management, contract obligations, arbitrage and uncommitted LNG. The model maximizes the profit mainly by taking advantage of price differences between different markets.

The contributions of this work are twofold. First, following the analysis of expenses and revenues, a new mixed integer programming model for LNG liquefaction and shipping is proposed from a corporate finance perspective. Furthermore, a solution approach for it is implemented and tested. Second, the model is used to derive a short term trade policy for the Middle Eastern LNG producers regarding the spot sale of their uncommitted product to Japan or to the UK, namely to: dispatch to whichever market has the higher current spot price, regardless of the variability of the transport expenses.

Keywords: LNG, operational planning, EBITDA, inventory routing problem, spot sale

\section{Introduction}

Natural gas, given its favourable environmental properties and substantial untouched reserves, is a vital primary energy source. It is well-placed to supply the world's increasing energy demand and to replace more polluting primary energy sources, such as coal and oil (Moniz et al., 2011). About onethird of the total natural gas produced in 2014 was exported internationally. There are two ways of exporting natural gas: via pipelines for near markets, and by sea in its liquid form, known as liquefied-natural-gas (LNG), for distant markets. Liquefying natural gas and exporting it by deep-sea vessels becomes economically more viable than the use of off-shore pipelines, if the gas market is farther than about 1,100 kilometres $(\mathrm{km})$. In economic terms, the equivalent distance for on-shore pipelines is approximately 3,500 km (Michot Foss, 2007). The importance of LNG is rising as demand for it grows faster than demand for pipeline gas (Hawk et al., 2013). LNG is delivered through a supply chain made of four phases: the first is gas extraction from the reserve. Liquefaction follows where gas is liquefied and is placed in storage tanks. Next, shipping is carried out by tankers. The final stage is regasification, where the LNG received is regasified and pumped into the trunk gas supply grid.

This work addresses the most profitable way of distributing LNG on a day-to-day basis. It does so by tackling the LNG inventory routing problem (LNG-IRP). This requires scheduling and dispatching the tanker fleet in order to fulfil the committed LNG cargo deliveries, while satisfying operational and inventory requirements. In addition, an efficient day-to-day LNG-IRP method should allow decisions to be made as to where to ship any uncommitted LNG and whether to divert any of the committed cargoes in order to take advantage of possible arbitrage opportunities.

The factors that need to be considered in profitable distribution of LNG can only be appreciated through an understanding of the business structure. Since its expansion in 1964, the global LNG trade has been based on long-term contracts (LTCS), with the duration of LTCs being 20-25 years (Hartley, 2013). Each LTC has two parties/sides: a producer or seller and a buyer or customer. An LNG project is developed based on a number of LTCs between the producer and several buyers; the

Abbreviations (alphabetically): ADP, annual delivery program; cash OPEX, cash parts of operating expenses; a CIF/DES-LTC buyer, an LTC buyer with CIF/DES delivery arrangement; a CIF/DES-LTC cargo delivery, a cargo delivery to the CIF/DES-LTC buyer; an FOB-LTC buyer, an LTC buyer with FOB delivery arrangement; LTC, longterm contract; an LTC buyer, a long-term contracted buyer. 
producer is responsible for developing the upstream liquefaction plant and the buyers are responsible for establishing the regasification terminals (Lee, 2005). Tankers for shipping may be owned by the producer, the buyers, or a third party, and may be dedicated to a specific LTC. Carriage is usually the responsibility of the producer (Ozelkan et al., 2008) with a cost-insurance-freight (CIF) or a delivered ex-ship (DES) contract, although the buyer may be responsible for carriage under a free-on-board (FOB) contract. The LTC is a sale and purchase agreement that ascertains and allocates the rights and obligations of the producer and the buyer. In the absence of a liquid LNG market, this agreement distributes the responsibilities for the main risks (price and volume risks) in developing an LNG project, between the producer and the buyer. There are two clauses in an LTC that assist in assigning and bounding these risks: the price clause that links the sale price to that of alternative energy sources at the buyer's market, and the take-or-pay clause that sets the minimum quantity for which the buyer must pay in each year of the contract, regardless of whether or not this quantity is actually taken. A third important LTC clause is the destination clause that seeks to prohibit a buyer from selling an LNG cargo, which is to be delivered to the principally identified regasification terminal/destination/market to any alternative market. Imposing the destination clause on CIF/DES contracts is easy and commonplace as the producer is responsible for the transport. Nevertheless, it has become an acceptable industry practice to divert LNG cargoes to other markets, to be sold on spot, with the mutual agreement of the LTC parties, subject to the agreement as to the split of the margin of arbitrage between the parties. According to Zhuravleva (2009), if the producer suggests the arbitrage, he might have to replace the diverted cargo for the buyer. For further discussions on business structure in LNG trade see, e.g., Nikhalat-Jahromi et al. (2015) and for statistics on LNG trade see, e.g., IGU (2015).

In an LNG project three different levels of planning are carried out by the producer in integrated LNG liquefaction and shipping: strategic (long-term), tactical (mid-term), and operational (short-term) planning. Only the last is of interest to this work.

Operational planning, i.e. day-to-day LNG-IRP, has not been the subject of much research. (For a survey of IRPs, including LNG-IRPs, see: Andersson et al., 2010a; and, Coelho et al., 2013). Fodstad et al. (2010) consider an operational LNG-IRP and formulate it as a mixed integer programming (MIP) model. In it, LNG tankers are scheduled and dispatched, while satisfying storage and operational requirements (e.g., technical problems with vessels that make them unavailable) and exploiting spot sale opportunities, in order to maximize the profit. The model developed was specifically tailored to address a practical problem faced by Statoil and GDF SUEZ. Therefore, it takes into consideration very specific and unusual factors, such as, cargo deliveries to buoy ports that can only be carried out by tankers with on board regasification equipment, and partial cargo deliveries. Such deliveries are seldom appropriate in LNG sector, since buoy ports and tankers with on board regasification equipment are uncommon, likewise, partial cargo deliveries are rare due to economic and safety reasons. Consequentially, the resulting model is extremely large and complicated, which explains the lack of follow-up academic research.

This paper focuses on operational planning. Its intended contributions are two-fold and can be divided into academic and industrial. An original and easy-to-understand model for the operational LNG-IRP is developed, accounting for the essential factors in such planning at the current global LNG trade, together with a solution approach to solve it. The authors take a corporate finance perspective, thus using a detailed analysis of the revenue and expense elements of the LNG producer enterprise. The model is used for deriving a trade rule (policy) in choosing the proper spot market between Japan and the UK, two prominent spot LNG importers, for spot sale of uncommitted LNG from Middle East, the biggest LNG supply region in the world. The remainder of this paper is structured as follows. Section 2 describes the planning problem. Section 3 examines spot sale of LNG from Oman to Japan and the UK, based on an LNG project inspired by data from 
industry and existing literature. Finally, Section 4 outlines the conclusions along with a policy suggestion and provides some topics for future research.

\section{Methods: an operational LNG-IRP}

\subsection{Problem description}

The foundation is an LNG project in which a producer supplies several long-term contracted buyers (termed LTC buyers) considering both types of cargo delivery arrangements, i.e. CIF/DES and FOB. Arbitrage is permitted with mutual agreement of both LTC sides and it has two types: arbitrage type one, which is suggested by the LNG producer where he needs to replace the arbitraged cargo for the LTC buyer with the CIF/DES delivery arrangement (hereafter the CIF/DES-LTC buyer)-arbitrage is defined for LTCs with destination clauses. And arbitrage type two, which can be suggested by any party but without involving any replacement. Surplus LNG, which is uncommitted to LTCs, can be sold on spot. Note that carrying out LTC deliveries and exploiting spot sale opportunities are essentially the LNG producer's major decisions.

A fleet of heterogeneous tankers is controlled by the LNG producer. The fleet consists of two types: fixed tankers, which are owned either by the producer or by the LTC buyers, or are long-term contracted by the producer; and spot tankers, which are spot chartered by the producer for one trip. Tankers leave the LNG liquefaction plant full and deliver their whole cargo to a regasfication terminal (direct delivery policy is a common practice in LNG sector). Unless contractually forbidden, fixed tankers can be used for any cargo delivery, i.e., uncommitted product, arbitrage and CIF/DES-LTC deliveries. Spot tankers can also be used for any cargo delivery. Each tanker has its own specific capacity and travelling speed. There are a limited number of berths available at the LNG liquefaction plant, therefore if a tanker arrives when there is no free berth it has to stay at anchor. The LNG producer keeps a safety inventory volume in the liquefaction plant's storage tanks. This volume is used for satisfying the LTC buyer's demands in the event of an unexpected failure in the plant.

The goal of modelling, profit maximization for the LNG producer enterprise, is achieved by maximizing the earnings before interest, tax, depreciation, and amortization (EBITDA), a measure of an enterprise's ability to produce profit on its operations, in corporate finance (Damodaran, 2012). The EBITDA is a suitable metric for short term operational decision making within a longer term financial structure in many infrastructure projects. This metric is obtained by deducting from the revenues resulting from the LNG sales, the cash components of operating expenses (termed cash OPEX) generated by the expenses of the liquefaction plant, tanker fleet, and cargo replacement in arbitrage. This work only considers the revenue and cash OPEX components which depend on the operational decisions of the LNG producer.

\subsubsection{Revenues from sale of $L N G$}

For LTC cargo deliveries the time and volume are fixed and established in the annual delivery program (ADP). Note that the ADP is put together by the producer by addressing the LNG-IRP in tactical level of planning, i.e., the tactical LNG-IRP. Geopolitical developments such as political unrest in the LNG producer country, as occurred in Egypt during the Arab spring, or a naval blockade, e.g., in Strait of Hormuz resulting from struggles between Iran and the US, may have implications regarding the LTC deliveries. However, such developments or others resulting in changed time and/or volume for these deliveries are negotiated by the LNG producer and the LTC buyers and are out of the scope of the operational planning. Nevertheless, the model developed here can evaluate the feasibility of the changes agreed upon. The revenues of these compulsory cargo deliveries are determined by the price clause, given the time and volume. Exceptions occur when, with a short notice, a CIF/DES cargo is arbitraged. Thus, the revenue of the deliveries carried out as planned are 
independent from the decisions of the LNG producer in operational planning. In contrast, the revenues of LNG spot sales are determined by the operational decisions.

In brief, the total revenues that are considered are those obtained through arbitrage and those from selling previously uncommitted LNG. The arbitrage revenue, a.k.a. margin of arbitrage, is the share of the producer in spot sale of the arbitraged cargo net of the previously expected CIF/DES-LTC cargo delivery revenue.

\subsubsection{Expenses of the liquefaction plant}

The plants are extremely capital intensive facilities and the assumption in developing and running them is that the LNG production occurs at full capacity at all times, unless the plant is turned-off for a scheduled overhaul or there is an unexpected failure (Rakke et al., 2011). Neither overhaul nor failure are factors under the control of the LNG producer in operational planning. Therefore, the LNG production capacity of the liquefaction plant is input for the operational level. Consequently, all the cash OPEX of the parts of the liquefaction plant that deal with liquefying natural gas are fixed for the LNG producer and are independent of the decisions in operational planning.

With regards to the remainder of the liquefaction plant, that is the storage tanks, cash OPEX is divided into fixed cash OPEX and variable cash OPEX. Fixed cash OPEX, including periodic maintenance, personnel and insurance expenses, are out of the scope of day-to-day LNG liquefaction. The variable cash OPEX for the storage tanks, resulting from circulation of LNG in the tanks and re-liquefaction of the boil-off from the tanks, are related to the volume of LNG kept in the storage tanks and thus are considered in operational planning.

\subsubsection{Expenses of the tanker fleet|shipping}

Fixed tankers: according to Stopford (2009), the expenses of an owned tanker can be divided into four main categories: (i) capital costs, which often include periodic payments to the lender banks and equity-investors that financed the purchase of the vessel; (ii) periodic maintenance costs, for dry-docking and surveys; (iii) operating costs, comprising of manning, stores, routine repairs, insurance, and administration fees; and (iv), voyage costs, generated by fuel costs, port charges, and canal dues. In this work, only costs of category (iv) are taken into account, since category (i) costs are out of the EBITDA's scope and categories (ii) and (iii) are fixed cash OPEX.

The fleet of LNG project's fixed tankers includes long-term contracted vessels. Two types of agreement are used in long-term contracting LNG tankers: time charter and bareboat charter contracts. In time chartering, the vessel owner, for a fixed charter rate per day, month or year, operates the tanker for the charterer, i.e., the LNG producer. In addition to the charter rate, the charterer pays the voyage costs too. In bareboat chartering, the charterer operates the vessel and pays the periodic maintenance, operating and voyage costs in addition to a fixed charter rate (Stopford, 2009). Therefore, since only variable cash OPEX are considered in EBIDTA calculation in this work, only the voyage costs of long-term contracted tankers are of interest.

Spot chartered tankers: to the knowledge of the authors, voyage charter contracts are used for tanker spot chartering in the LNG sector. The spot charter fee may be an agreed amount for a particular voyage or a cargo related rate, typically in US dollar-per-tonne (\$/tonne) or US dollar-permillion British thermal units (\$/MMBtu). Since this is variable cash OPEX, it needs to be taken into account. Note that, in arbitrage, the tanker expenses are the variable cash OPEX in shipping to the arbitrage market net of that in shipping to the primary market. 


\subsubsection{Expense of cargo replacement in arbitrage}

Given the type of arbitrage, the LNG producer might need to replace the cargo for the LTC buyer. As this need is generated by the decisions made in operational planning, it is a variable cash OPEX and thus must be taken into account.

The time value of money is not taken into account in this work. Since the very short time horizon in operational planning results in marginal and negligible effects for this factor in the decisions made. Note that, the typical time horizon is three months, however the plan is renewed usually every twoweeks to one month on a rolling horizon basis (Andersson et al., 2010b).

\subsection{Mathematical model formulation and implementation}

The mathematical and solution details in Subsections 2.2 and 2.3 may be omitted at a first reading by those whose main interest lies in the general description of this model and its application to developing a trade rule for the spot sale of uncommitted Middle Eastern LNG.

An original MIP model is developed in this work. Maritime IRPs, given the types of decision associated with them, are generally formulated as MIP models (Christiansen and Fagerholt, 2009). Let $D$, indexed by $d$ and $g$, be the set of all the regasification terminals/markets/destinations for LTC, arbitrage, and uncommitted product deliveries. The set of CIF/DES-LTC buyers' destinations is defined as $D^{C}$, where $D^{C} \subseteq D$. Consider a planning horizon $H$, indexed by $h$, and two arbitrage types indexed by $a \in A=\{1,2\}$. Finally, let $T$, indexed by $t$, be the tanker fleet, where the disjoint sets $\widehat{T}$ and $\breve{T}$ represent, respectively, the fixed and spot tankers $(\widehat{T} \cup \breve{T}=T)$.

The parameters used in the model formulation are presented in Table 1 and the decision variables are characterized in Table 2.

Table 1 - Problem parameters (alphabetically).

\begin{tabular}{|c|c|}
\hline Parameter & Definition \\
\hline$B$ & Number of berths at the LNG liquefaction plant. \\
\hline$E_{h}^{I}$ & $\begin{array}{l}\text { Storage tanks' expenses }\left[\$ / \text { cubic-meters }\left(\mathrm{m}^{3}\right)\right] \text { at the plant on day } h \text {; these are the expenses } \\
\text { associated with the circulation of LNG in the tanks and re-liquefaction of the boil-off, a.k.a. } \\
\text { variable cash OPEX for the storage tanks. }\end{array}$ \\
\hline$E_{h t d}^{S}$ & $\begin{array}{l}\text { Expenses (\$) of shipping from the plant to destination } d \text {, by tanker } t \text { that leaves on day } h \text {. This is } \\
\text { the voyage costs for the fixed tankers and the spot chartering fee for the spot tankers, a.k.a. } \\
\text { variable cash OPEX for the tankers. }\end{array}$ \\
\hline$E_{h d a}^{R}$ & $\begin{array}{l}\text { Replacement expenses ( } \$ / \mathrm{MMBtu}) \text { for the LNG arbitraged, with an arbitrage type } a \text {, where the } \\
\text { replacement cargo is received in CIF/DES-LTC buyer's destination } d \text { on day } h ; E_{h d 2}^{R}=0 \text {, for all } h \\
\text { and } d \text {. }\end{array}$ \\
\hline$F_{h}$ & Number of the FOB-LTC buyers' tankers arriving in the plant on day $h$ for taking $K_{h}^{F}$. \\
\hline$I^{0}$ & Volume of LNG $\left(\mathrm{m}^{3}\right)$ in the plant's storage tanks at the beginning of the time horizon planned. \\
\hline$\underline{I}$ & Minimum permitted inventory volume $\left(\mathrm{m}^{3}\right)$ at the plant's storage tanks. \\
\hline$I^{M}$ & Safety inventory volume $\left(\mathrm{m}^{3}\right)$ at the plant's storage tanks. \\
\hline $\bar{I}$ & Maximum inventory volume $\left(\mathrm{m}^{3}\right)$ at the plant's storage tanks. \\
\hline$J$ & Density of LNG, usually 0.45 tonnes/ m³ (IGU, 2012). \\
\hline$K_{h d}^{C}$ & $\begin{array}{l}\text { Demand of a CIF/DES-LTC buyer (tonne), designated in ADP, that shall be fulfilled with a cargo } \\
\text { delivery(s), by the LNG producer's tanker fleet, received on day } h \text { at the buyer's destination } d \text {. } \\
K_{h d}^{C} \text { is a multiple of fixed tanker's capacity, considering boil-off in the tankers. }\end{array}$ \\
\hline$K_{h}^{F}$ & $\begin{array}{l}\text { Sum of FOB-LTC buyers' demands (tonne) on day } h \text { that is taken from the plant by the buyers' } \\
\text { tankers. }\end{array}$ \\
\hline$L$ & Conversion rate of MMBtu to tonne for LNG; each MMBtu is usually 0.0187 tonnes (IGU, 2012). \\
\hline
\end{tabular}




\begin{tabular}{|c|c|}
\hline$N_{h d}^{C}$ & $\begin{array}{l}\text { Binary parameter defined related to } Q_{h d}^{C} \text { that determines the arbitrage type. For arbitrage } \\
\text { type } 1, N_{h d}^{C}=1 \text {, and for arbitrage type } 2 \text { it is zero. }\end{array}$ \\
\hline$O_{t}^{B}$ & Boil-off rate (\%/day) of tanker $t$ in ballast leg of its trips. \\
\hline$O_{t}^{L}$ & Boil-off rate (\%/day) of tanker $t$ in laden leg of its trips. \\
\hline$P_{h}$ & Production capacity of the plant (tonne) on day $h$. \\
\hline$Q_{h d}^{C}$ & Amount (\%) of $K_{h d}^{C}$ that the relative CIF/DES-LTC buyer is willing to arbitrage. \\
\hline$R_{\text {hdga }}^{A}$ & $\begin{array}{l}\text { Revenue (margin of arbitrage) for the producer (\$/MMBtu) in arbitrage of LNG from } \\
\text { destination } d \text { to destination } g \text {, with arbitrage type } a \text {, dispatched from the plant on day } h \text {. }\end{array}$ \\
\hline$R_{h d}^{U}$ & $\begin{array}{l}\text { Revenue (spot price) for the producer (\$/MMBtu) in sale of uncommitted LNG dispatched to } \\
\text { destination } d \text { on day } h \text {. }\end{array}$ \\
\hline$S_{t d}\left(=S_{t d}^{L}+S_{t d}^{B}\right)$ & $\begin{array}{l}\text { Shipping time (day) for the return trip between the plant and destination } d \text { by tanker } t \text {. Here, } \\
S_{t d}^{L} \text { is the laden leg (including loading time), and } S_{t d}^{B} \text { is the ballast leg (including discharging } \\
\text { time). }\end{array}$ \\
\hline$U_{h t}$ & $\begin{array}{l}\text { Binary parameter that describes unavailability }\left(U_{h t}=0\right) \text { of tanker } t \text { on day } h . U_{h t} \text { by default } \\
\text { is equal to one, meaning the tanker is available, unless defined equal to zero. }\end{array}$ \\
\hline$V_{d}$ & Capacity $\left(\mathrm{m}^{3}\right)$ of the maximum tanker that can be served at destination $d$. \\
\hline$V_{t}$ & Capacity of tanker $t\left(\mathrm{~m}^{3}\right)$ \\
\hline$W$ & penalty $(\$)$ of shortage in the safety inventory volume. \\
\hline
\end{tabular}

Table 2 - Decision variables (alphabetically).

\begin{tabular}{|c|c|c|}
\hline $\begin{array}{l}\text { Decision } \\
\text { variable }\end{array}$ & Type & Definition \\
\hline$i_{h}$ & Continuous & Volume of LNG $\left(\mathrm{m}^{3}\right)$ at the liquefaction plant's storage tanks at the end of day $h$. \\
\hline$m_{h}$ & Binary & One if $i_{h}$ falls below $I^{M}$; zero otherwise. \\
\hline$x_{h t d}$ & Binary & $\begin{array}{l}\text { One if there is a CIF/DES-LTC cargo delivery to destination } d \text { by tanker } t \text { that is } \\
\text { leaving the plant on day } h \text {; zero otherwise. }\end{array}$ \\
\hline$y_{\text {htdga }}$ & Binary & $\begin{array}{l}\text { One if on day } h \text { the cargo that was to be delivered to destination } d \text { is diverted to } \\
\text { destination } g \text {, by an arbitrage type a, using tanker } t \text {, zero otherwise. }\end{array}$ \\
\hline$Z_{\text {htd }}$ & Binary & $\begin{array}{l}\text { One if there is an uncommitted product cargo delivery to destination } d \text { by tanker } \\
t \text { leaving the plant on day } h \text {; zero otherwise. }\end{array}$ \\
\hline
\end{tabular}

\subsubsection{Objective function}

The objective function, which has six components, maximizes the EBITDA over the course of the planning time horizon. Components (1.1) and (1.2) represent the revenues in spot sale of uncommitted product and arbitrage, considering the boil-off in laden and ballast trips of the tankers. The other four components are expenses: component (1.3) refers to the expenditure incurred with the replacement of arbitraged CIF/DES-LTC cargo deliveries. Component (1.4) represents the shipping expenses incurred in all cargo deliveries. The last two components (1.5) refer to inventory expenditures, namely the storage tanks expenses and a penalty for shortage in the safety inventory volume. This penalty prevents the usage of safety inventory under normal circumstances when there is no failure in the liquefaction plant.

$$
\begin{aligned}
M A X & \sum_{h \in H} \sum_{t \in T} \sum_{d \in D} R_{h d}^{U} L J V_{t}\left[1-\left(O_{t}^{L} S_{t d}^{L}+O_{t}^{B} S_{t d}^{B}\right)\right] z_{h t d} \\
& +\sum_{h \in H} \sum_{t \in T} \sum_{d \in D^{C}} \sum_{g \in D} \sum_{a \in A} R_{h d g a}^{A} L J V_{t}\left[1-\left(O_{t}^{L} S_{t g}^{L}+O_{t}^{B} S_{t g}^{B}\right)\right] y_{h t d g a} \\
& -\sum_{h \geq S_{t d}^{L}+1} \sum_{t \in T} \sum_{d \in D^{C}} \sum_{g \in D} \sum_{a \in A} E_{h t a}^{R} L J V_{t}\left[1-\left(O_{t}^{L} S_{t d}^{L}+O_{t}^{B} S_{t d}^{B}\right)\right] y_{\left(h-S_{t d}^{L}\right) t d g a} \\
& -\sum_{h \in H} \sum_{t \in T} \sum_{d \in D^{C}} E_{h t d}^{S} x_{h t d}-\sum_{h \in H} \sum_{t \in T} \sum_{d \in D^{C}} \sum_{g \in D} \sum_{a \in A}\left(E_{h t g}^{S}-E_{h t d}^{S}\right) y_{h t d g a}-\sum_{h \in H} \sum_{t \in T} \sum_{d \in D} E_{h t d}^{S} z_{h t d}
\end{aligned}
$$




$$
-\sum_{h \in H} E_{h}^{I} i_{h}-\sum_{h \in H} W m_{h}
$$

\subsubsection{Constraints for liquefaction plant's storage tanks}

Constraints (2) are the balance constraints. Constraints (3) limit the LNG volume in the storage tanks, and constrains (4) flag an LNG volume in the storage tanks bellow $I^{M}$.

$i_{h}=i_{h-1}+\left(\frac{P_{h}}{L}\right)-\sum_{t \in T} \sum_{d \in D^{C}} V_{t} x_{h t d}-\sum_{t \in T} \sum_{d \in D^{C}} \sum_{g \in D} \sum_{a} V_{t} y_{h t d g a}-\sum_{t \in T} \sum_{d \in D} V_{t} z_{h t d}-\left(\frac{K_{h}^{F}}{L}\right) . \quad \forall h \in H$

$\underline{I} \leq i_{h} \leq \bar{I} . \quad \forall, h \in H$

$I^{M}-i_{h} \leq I^{M} m_{h} . \quad \forall, h \in H$

\subsubsection{Constraints for fulfilment and arbitrage of CIF/DES-LTC cargo deliveries}

The CIF/DES-LTC buyers' demands ought to be fulfilled [constraints (5)], unless arbitraged [constraints (6)] through arbitrage types [constraints (7)].

$\frac{K_{h d}^{C}}{L}\left(1-Q_{h d}^{C}\right) \leq \sum_{t \in T} V_{t} x_{\left(h-S_{t d}^{L}\right) t d}\left[1-\left(O_{t}^{L} S_{t d}^{L}+O_{t}^{B} S_{t d}^{B}\right)\right] \leq \frac{K_{h d}^{C}}{L}, \quad \forall, h \in H \mid h \geq S_{t d}^{L}+1, d \in D^{C}$.

$\frac{K_{h d}^{C}}{L}-\sum_{t \in T} V_{t} x_{\left(h-S_{t d}^{L}\right) t d}\left[1-\left(O_{t}^{L} S_{t d}^{L}+O_{t}^{B} S_{t d}^{B}\right)\right]=\sum_{t \in T} \sum_{g \in D} \sum_{a \in A} V_{t} y_{\left(h-S_{t d}^{L}\right) t d g a}\left[1-\left(O_{t}^{L} S_{t d}^{L}+O_{t}^{B} S_{t d}^{B}\right)\right]$,

$$
\forall, h \in H \mid h \geq S_{t d}^{L}+1, d \in D^{C} .
$$

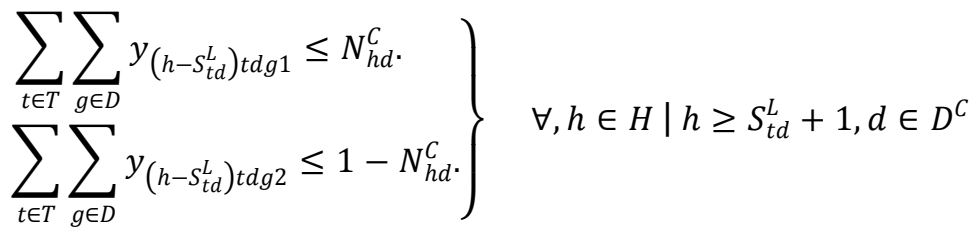

\subsubsection{Constraints for berthing services}

Berth capacity at the destination and berth availability at the plant are ensured by constraints (8) and (9), respectively.

$$
\begin{aligned}
& V_{t} x_{h t d} \leq V_{d} . \quad \forall, h \in H, t \in T, d \in D^{C} \\
& V_{t} y_{h t d g a} \leq V_{g} . \quad \forall, h \in H, t \in T, d \in D^{C}, g \in D, a \in A \\
& V_{t} z_{h t d} \leq V_{d} . \quad \forall, h \in H, t \in T, d \in D \\
& \sum_{t \in T} \sum_{d \in D^{C}} x_{h t d}+\sum_{t \in T} \sum_{d \in D^{C}} \sum_{g \in D} \sum_{a \in A} y_{h t d g a}+\sum_{t \in T} \sum_{d \in D} z_{h t d}+F_{h} \leq B . \quad \forall, h \in H
\end{aligned}
$$

\subsubsection{Constraints for tanker assignment to cargo deliveries}

Constraints (10) state that spot chartered tankers can do a single cargo delivery, while constraints (11) ensure that fixed tankers are assigned to at most one cargo delivery type.

$$
\sum_{h \in H} \sum_{d \in D^{C}} x_{h t d}+\sum_{h \in H} \sum_{d \in D^{C}} \sum_{g \in D} \sum_{a \in A} y_{h t d g a}+\sum_{h \in H} \sum_{d \in D} z_{h t d} \leq 1 . \quad \forall, t \in \check{T}
$$


$\sum_{d \in D^{C}} x_{h t d}+\sum_{d \in D^{C}} \sum_{g \in D} \sum_{a \in A} y_{h t d g a}+\sum_{d \in D} z_{h t d} \leq 1 . \quad \forall, h \in H, t \in \hat{T}$

Constraints (12) to (14) enforce that assigned fixed tankers remain assigned until the return trip is concluded, for CIF/DES-LTC, arbitrage, and uncommitted cargo deliveries, respectively.

$$
\begin{aligned}
& S_{t d} x_{h t d}+\sum_{\left\{\varphi \in \left\{h, \ldots, h+S_{\left.\left.t d^{-1}\right\}|\varphi \leq| H \mid\right\}}\right.\right.} \sum_{d \in D^{C}} x_{\varphi t d}+\sum_{\left\{\varphi \in\left\{h, \ldots, h+S_{t d}-1\right\}|\varphi \leq| H \mid\right\}} \sum_{d \in D^{C}} \sum_{g \in D} \sum_{a \in A} y_{\varphi t d g a} \\
& +\sum_{\left\{\varphi \in\left\{h, \ldots, h+S_{t d}-1\right\}|\varphi \leq| H \mid\right\}} \sum_{d \in D} z_{\varphi t d} \leq S_{t d}+1 . \quad \forall, h \in H, t \in \widehat{T}, d \in D^{C} \\
& S_{t g} y_{\text {htdga }}+\sum_{\left\{\varphi \in \left\{h, \ldots, h+S_{\left.\left.t d^{-1}\right\}|\varphi \leq| H \mid\right\}}\right.\right.} \sum_{d \in D^{C}} x_{\varphi t d}+\sum_{\left\{\varphi \in\left\{h, \ldots, h+S_{t d}-1\right\}|\varphi \leq| H \mid\right\}} \sum_{d \in D^{C}} \sum_{g \in D} \sum_{a \in A} y_{\varphi t d g a} \\
& +\sum_{\left\{\varphi \in\left\{h, \ldots, h+S_{t d}-1\right\}|\varphi \leq| H \mid\right\}} \sum_{d \in D} z_{\varphi t d} \leq S_{t g}+1 . \quad \forall, h \in H, t \in \widehat{T}, d \in D^{C}, g \in D, a \in A \\
& \begin{array}{r}
S_{t d} z_{h t d}+\sum_{\left\{\varphi \in \left\{h, \ldots, h+S_{\left.\left.t d^{-1}\right\}|\varphi \leq| H \mid\right\}}\right.\right.} \sum_{d \in D^{C}} x_{\varphi t d}+\sum_{\left\{\varphi \in\left\{h, \ldots, h+S_{t d}-1\right\}|\varphi \leq| H \mid\right\}} \sum_{d \in D^{C}} \sum_{g \in D} \sum_{a \in A} y_{\varphi t d g a} \\
+\sum_{\left\{\varphi \in\left\{h, \ldots, h+S_{t d}-1\right\}|\varphi \leq| H \mid\right\}} \sum_{d \in D} z_{\varphi t d} \leq S_{t d}+1 . \quad \forall, h \in H, t \in \widehat{T}, d \in D^{C}
\end{array}
\end{aligned}
$$

\subsubsection{Constraints for tankers unavailability}

Constraints (15) make sure that unavailable tankers are not assigned to any cargo delivery.

$$
\begin{aligned}
& \sum_{d \in D^{C}} x_{h t d} \leq U_{h t} \cdot \\
& \sum_{d \in D^{C}} \sum_{g \in D} \sum_{a \in A} y_{h t d g a} \leq U_{h t} \cdot \\
& \sum_{d \in D} z_{h t d} \leq U_{h t} .
\end{aligned} \forall, h \in H, t \in T
$$

\subsubsection{Constraints for defining the nature of decision variables}

$$
\left.\begin{array}{l}
i_{h} \geq 0 . \quad \forall, h \in H \\
m_{h} \in\{0,1\} . \quad \forall, h \in H \\
x_{h t d} \in\{0,1\} . \quad \forall, h \in H, t \in T, d \in D^{C} \\
y_{h t d v s} \in\{0,1\} . \quad \forall, h \in H, t \in T, d \in D^{C}, g \in D, a \in A \\
z_{h t d} \in\{0,1\} . \quad \forall, h \in H, t \in T, d \in D
\end{array}\right\}
$$

\subsection{Solution approach}

The model is programmed in and is optimized by ILOG CPLEX Optimization Studio 12.6.1, while for each time horizon the data is read from and results are exported to Excel spreadsheets. The resulting implementation, which is named the software for operational LNG liquefaction and shipping (abbreviated as SOLaS), involves pre- and post-processing procedures written in Excel by Microsoft 
Visual Basic. These routines play a significant role in planning consecutive time horizons on a rolling horizon basis in SOLaS.

Pre-processing: updates, at the beginning of the planning horizon, the initial inventory level, $I^{0}$, as well as the tankers unavailability, $U_{h t}$.

Post-processing: addresses both the penalty imposed on cutting into the safety inventory volume, and the eventual surplus or deficit in arbitraged LNG.

- The last component of the objective function imposes a fictitious penalty on cutting into the safety inventory volume, which, in case of occurring, has to be added back to the value of the objective function before it is reported.

- The difference in the shipping time of diverted cargoes with their original shipping time might lead to a small surplus/deficit in the LNG sold designated as $k_{h d}^{C}$, see equation (17). Whenever the accumulated value, over multiple time horizons, becomes meaningful it is settled, with mutual agreement of the LTC sides, as an amendment to the buyer's demand profile. Otherwise it can be dealt with as a cash transaction in the end of ADP.

$$
\begin{array}{r}
\frac{K_{h d}^{C}}{L}-\sum_{t \in T} V_{t} x_{\left(h-S_{t d}^{L}\right) t d}\left[1-\left(O_{t}^{L} S_{t d}^{L}+O_{t}^{B} S_{t d}^{B}\right)\right]-\sum_{t \in T} \sum_{g \in D} \sum_{a \in A} V_{t} y_{\left(h-S_{t d}^{L}\right) t d g a}\left[1-\left(O_{t}^{L} S_{t g}^{L}+O_{t}^{B} S_{t g}^{B}\right)\right]=k_{h d}^{C} . \\
\left\{\forall, h \in H \mid h \geq S_{t d}^{L}+1, d \in D^{C}\right\} \mid Q_{h d}^{C}>0
\end{array}
$$

It was noted before that the operational plan is usually renewed every two-weeks to one month. However, due to unexpected events, such as reduction in LNG output, a technical problem with a fixed tanker, or a sharp change in spot prices, an earlier rolling of the time horizon may be required. This is accomplished by stopping the execution of the plan, modifying the data parameters to consider the incident(s), and running SOLaS to obtain a new plan, which is then used.

\section{Numerical analysis and discussion}

\subsection{An LNG project inspired by data from industry and existing literature}

The practical use of the model is illustrated by a real world decision-making problem in an LNG project. The project settings and scenarios are briefly described here, the reasons behind the choices, and all other details are provided as supplementary material in Appendix A.

Consider an LNG producer in Middle East, the biggest regional source of LNG supply in the world, whose entire production is dedicated to two LTC buyers on CIF/DES arrangement in Asia and NorthAmerica. The plant is assumed to be in Oman at Qalhat and the regasification terminals are respectively located at Incheon in South Korea and at Everett in the US, which indeed all host real LNG facilities. Table 3 presents the list of LTC deliveries to these destinations for the next three months. The distance between the facilities in Oman and South Korea is 5,641 nautical miles (NMs) and between them in Oman and the US, through the Suez Canal, is 7,510 NMs. Further, consider Japan and the UK, two prominent spot LNG importers, as the potential spot markets for the project. The average distance between the British major regasification terminals, i.e., Grain, Dragon, and South Hook, and the Omani liquefaction plant, via the Suez Canal, is 5,665 NMs; while this distance for the key Japanese terminals, i.e., Sodeguara, Senboku, Negishi, Futtsu, and Higashi-Ohgishima is 5,944 NMs (Sea Rates, 2015). 
Table 3 - List of CIF/DES-LTC cargo deliveries according to the ADP.

\begin{tabular}{cccc}
\hline No. & Delivery day & Destination & Magnitude (tonnes) \\
\hline 1 & 17 & Incheon & 74,250 \\
2 & 26 & Everett & 74,250 \\
3 & 28 & Incheon & 74,250 \\
4 & 30 & Everett & 74,250 \\
5 & 32 & Incheon & 74,250 \\
6 & 39 & Incheon & 74,250 \\
7 & 41 & Everett & 74,250 \\
8 & 48 & Everett & 74,250 \\
9 & 51 & Incheon & 74,250 \\
10 & 52 & Everett & 74,250 \\
11 & 54 & Incheon & 74,250 \\
12 & 62 & Incheon & 74,250 \\
13 & 63 & Everett & 74,250 \\
14 & 65 & Incheon & 74,250 \\
15 & 74 & Everett & 74,250 \\
16 & 78 & Everett & 74,250 \\
17 & 80 & Incheon & 74,250 \\
18 & 82 & Everett & 74,250 \\
19 & 88 & Incheon & 74,250 \\
20 & 89 & Everett & 74,250 \\
\hline
\end{tabular}

This project, in the next subsection, is used for creating a trade rule, through sensitivity tests on a single time horizon with the length of three months, for spot sale of uncommitted Omani LNG to the two aforementioned spot markets, for the near future (2015 up-to 2020). Looking further due to the uncertainty in prediction of the factors involved is not pursued, however, the methodology of this work can be used for deriving the same rule for farther periods, later with having more accurate data.

The plant is assumed to have a daily production capacity of 20,000 tonnes of LNG, two storage tanks holding up to $140,000 \mathrm{~m}^{3}$ each, and a single berth. The fleet consists of 10 fixed tankers, each having an average speed of 19.5 knots and capable of carrying 165,000 $\mathrm{m}^{3}$ of LNG. The return trip durations to South Korea, US, Japan and UK have been calculated to approximately, 26, 36, 28 and 28 days, respectively. Each tanker burns 150 tonnes of fuel oil equivalent (FOE) per day on the laden voyage and 135 tonnes of FOE per day on the ballast voyage. The port charges for a return trip have been estimated to be $\$ 300,000$ (Androsova, 2015) and the Suez Canal fee is $\$ 850,000$. Regarding the FOE, the fuel oil needs are only about half of what is burnt since the other half comes from the natural boil-off. Currently the fuel oil of choice for LNG tankers is intermediate fuel oil (IFO) 380. In the sensitivity tests ahead, three price scenarios for IFO 380 are considered. These are defined, based on the predicted oil prices for near future, as: the floor: $\$ 146 /$ tonne, the middle: $\$ 240 /$ tonne, and the cap: \$333/tonne scenarios.

LNG spot prices are highly volatile and therefore very difficult to predict. In this research, a floor price of $\$ 4 / M M B t u$ is assumed, since this is the record low spot price experienced by both the UK and Japan. Nine scenarios corresponding to nine ordered pairs of price (UK, Japan) are considered, with differences ranging from $-\$ 8 / \mathrm{MMBtu}$ to $\$ 8 / \mathrm{MMBtu}$, in multiples of two: $\mathrm{A}(12,4), \mathrm{B}(10,4), \mathrm{C}$ $(8,4), D(6,4), E(4,4), F(4,6), G(4,8), H(4,10)$, and I $(4,12)$.

\subsection{A trade rule for spot sale of uncommitted LNG from Oman to Japan and UK}

Considering the variable factors defined above, i.e. LNG spot price and fuel oil price, this subsection focuses on interaction of these two, and aims to derive a trade rule. The LNG producer enterprises in 
Middle East are in close proximity and operate in the same commercial climate. Hence, any rule derived for Oman can be extended to the whole region.

The model was solved for all 27 combinations of IFO 380 and LNG spot price scenarios. Note that for the sake of sensitivity tests in this subsection, LTC cargo delivery no. 7 in Table 3 is removed and assumed to be uncommitted. Figure 1 summarizes the results obtained, while detailed results are presented in Appendix A: supplementary material. As it is observed, somewhere between spot price scenarios $D$ and $E$ the spot market of choice changes, regardless of the price scenario for IFO 380.

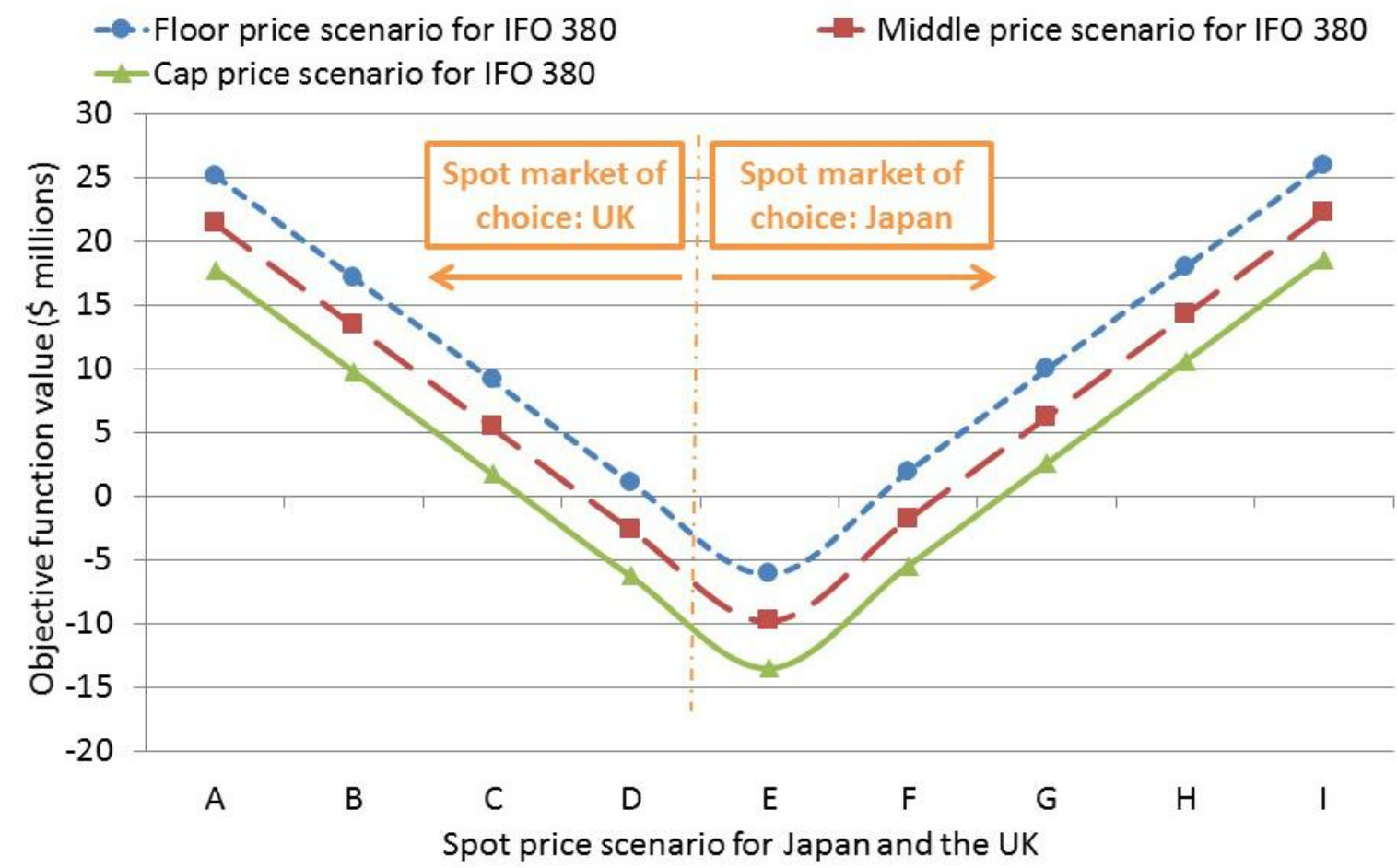

Figure 1 - Sensitivity test results in choosing the spot market for all the UK and Japan spot prices and IFO 380's price scenarios.

To determine where the decision on spot market choice changes, a new price scenario, designated as $D^{\prime}$, is defined with the UK and Japan spot prices, respectively, being $\$ 5 / \mathrm{MMBtu}$ and $\$ 4 / \mathrm{MMBtu}$. For this new scenario, and for all IFO 380's price scenarios the choice is the UK. Therefore, the cutoff line of market choice is in fact between $D^{\prime}$ and $E$. Next, a forced sale to Japan for spot price scenario $\mathrm{D}^{\prime}$ and to the UK for price scenario $\mathrm{E}$ is considered. Table 4 reports the objective function values with and without forced sales.

Table 4 - Comparison of objective function value (\$ millions) for unforced and forced spot sale.

\begin{tabular}{|c|c|c|c|c|}
\hline Item & spot price scenario & $\begin{array}{l}\text { Floor price for IFO } \\
380(\$ 146 / \text { tonne }) \\
\end{array}$ & $\begin{array}{c}\text { Middle price for IFO } \\
380(\$ 240 / \text { tonne })\end{array}$ & $\begin{array}{l}\text { Cap price for IFO } \\
380 \text { (\$333/tonne) }\end{array}$ \\
\hline \multirow{2}{*}{ Unforced spot sale } & $\mathrm{D}^{\prime}$ & -2.941 & -6.638 & -10.296 \\
\hline & $E$ & -6.076 & -9.786 & -13.457 \\
\hline \multirow{2}{*}{ Forced spot sale } & $D^{\prime}$ & -6.076 & -9.786 & -13.457 \\
\hline & $E$ & -6.905 & -10.602 & -14.260 \\
\hline \multirow{2}{*}{$\begin{array}{l}\text { The difference } \\
\text { between unforced } \\
\text { and forced sales }\end{array}$} & $D^{\prime}$ & 3.135 & 3.148 & 3.161 \\
\hline & $\mathrm{E}$ & 0.829 & 0.816 & 0.803 \\
\hline
\end{tabular}


As it can be seen, the objective function value differences, between the forced and unforced sales, for spot price scenario $E$ are very small. This suggests that in spot sale of uncommitted LNG from Oman/Middle East to Japan and the UK, regardless of the fuel oil price, the market with the higher LNG spot price should be picked. To evaluate this hypothesis in more detail, a further set of sensitivity tests with new spot price scenarios has been carried out. In the new scenarios, ranging between $\$ 5 / \mathrm{MMBtu}$ and $\$ 12 / \mathrm{MMBtu}$, the spot prices of the UK and Japan are equal. The difference between the objective function values in forced and unforced sales in all these tests for floor, middle and cap price scenarios of IFO 380 are, respectively, $\$ 0.829$ million, 0.816 million and $\$ 0.803$ million. Details of the tests are reported as supplementary material in Appendix A. Therefore, the aforementioned hypothesis is correct, as the difference is always small and never goes beyond $\$ 0.829$ million.

The observed differences in objective function value EBITDA (maximum $\$ 0.829$ million) are insignificant and could easily be exceeded by changes in factors such as the fuel consumption of an LNG tanker affected by weather and other unpredictable sea conditions, boil-off rate, etc. (Wang et al., 2014). These differences become even smaller and more trivial to the LNG producer enterprise considering that what really matters to an established enterprise's equity-holders and is their goal beyond tactical and operational planning, is the maximization of net-income in the end of each fiscal year. In calculating the net-income, the tax and royalty that together in Middle Eastern LNG projects are $25 \%-55 \%$ of EBITDA (Deloitte, 2015) are also deducted; hence $25 \%-55 \%$ of these differences does not belong to the enterprise to begin with. Here it is assumed that there is no interest expense on the income statement of the enterprise, since the repayment period of the loans received for financing the capital expenditures (CAPEX) of the projects in Middle East has long past. If a Middle Eastern enterprise has such an expense, resulting perhaps from borrowed money for financing its working capital, that would be deducted from EBITDA as well, then the observed differences would be even more inconsequential to net-income.

\section{Conclusions, policy implication and further research}

EBITDA has been selected as an appropriate measure for an LNG producer enterprise in operational decision-making in integrated liquefaction and shipping. A comprehensive analysis of the revenue and expense elements of the LNG producer shows that the following financial components are important in maximization of EBITDA/profit for the enterprise: (i) the revenues from spot sale of uncommitted product and from arbitrage, the latter are net of lost revenues due to cargo diversion; and (ii) the variable cash OPEX resulting from expenses of LNG circulation in the liquefaction plant's storage tanks and re-liquefaction of boil-off, replacement costs for cargoes arbitraged, tanker spot chartering fee, and fixed tankers' voyage costs, albeit net of saved tanker expenses for diverted LTC cargoes for the last two terms.

This analysis is followed by a state of the art MIP formulation which maximizes the revenues minus the variable cash OPEX. The formulation is programmed in and solved by ILOG CPLEX Optimization Studio 12.6.1 in combination with Excel. This implementation, which is named SOLaS, is/could be a very useful tool to LNG producers, since it makes use of a rich mathematical formulation, which considers an array of common issues in operational decision-making. The value of this tool is emphasized by the fact that many LNG producers still rely on manual planning and rules-of-thumbs in operational decision-making (Fodstad et al., 2010).

From the point of view of policy implication, using some sensitivity tests carried-out on a realistic LNG project, a simple yet elegant trade rule is derived: for the near future (2015 up-to 2020), a Middle Eastern LNG producer, deciding between spot sale of his uncommitted cargoes to Japan or to the UK, should dispatch it to whichever market that has a higher spot price. The tests indicate that 
the decision on choosing between these two major spot markets is relatively insensitive to the fuel oil price and to transport costs but rather depends on the LNG spot price. The suggested policy is consistent with the opinion of Jensen (2004), in that, it implies the Middle East, given its strategic geographical position, can be a swing supplier, within the range of reasonable price differences, to the two major LNG consumption regions of the world, Europe and Asia; while the other key LNG supply region, Asia-Pacific, has to focus on Asian markets. Details on interregional trade trends can be found in, e.g., IGU (2015).

There are several interesting ways in which this work could be extended; here three of them are outlined:

Model extension: (i) constraints (6) in Section 2 determine the arbitrage timing so that the cargo dispatched for the arbitrage destination may be delivered to the LTC buyer's regasification terminal at its designated time in the ADP. To the authors' knowledge this is a common arrangement given the logistical constraints, such as storage tanks capacity, in the LNG sector. However, there may be cases whereby dispatching does not occur in this way. An extension to the mathematical formulation could cover these states and permit arbitrage with other dispatch timings. (ii) There is a growing tendency among LNG producers for vertical integration of supply chain by including the regasification phase; a thorough discussion on this can be found in, e.g., Nikhalat-Jahromi et al. (2015). International oil companies such as BP and Shell have formed LNG portfolios, combining the supply of LNG from several liquefaction plants and using their tankers to feed into their regasification capacity across the world. Given these developments, extending the formulation for accommodating the supply from several enterprises, and managing the downstream regasification terminals in terms of berth, tank-farm, etc., may be useful.

Solution approach: (i) SOLaS, although a powerful tool, does not have a user-friendly interface. This makes it difficult for non-academics\planners to use it. Programming a graphical interface for it would pave the way for SOLaS to become a commercially viable product. (ii) SOLaS can manage realistic project sizes, since it took less than one minute to solve a project involving five destinations and 35 tankers while larger projects are unlikely. However, if the above suggested portfolio configuration for the formulation proves calculation-wise intractable, development of a heuristic algorithm becomes necessary.

Widening the scope of application (other trade rules for Middle East): (i) since 2008, as the result of surge in shale gas production in the US, the cargoes destined by many LTCs for North-America, a former major LNG consumption region, are arbitraged (Hartley, 2013). It would be interesting to create a trade rule for arbitrage of the cargoes from the US, sourced from Middle East, to the UK and Japan. In deriving such a rule, the calculation of margin of arbitrage requires the price for the LTC cargo in the US. Due to the vastness of the US, there is no single reference price for the LNG cargoes, but rather the price is linked to many local hubs in the country. For further discussion on the US LNG pricing see, e.g., Dickel et al. (2007). Thus, any rule created would be specific and related to the local hub of the destination regasification terminal for the LTC cargo, and not the whole country. Owing to this fact, there cannot be a single general rule but rather several rules, possibly as many as the number of local hubs associated with regasification terminals in the US. (ii) Rules similar to the one created in this work, and those suggested in the previous recommendation for further research, can be established for spot sale by spot chartered tankers. The complexity of deriving such rules comes from the uncertainty in spot tanker chartering fees, which are very volatile. 


\section{Acknowledgements}

* The authors would like to thank the editor and the referees for their helpful comments during the review process, furthermore, they appreciate the valuable contributions of the following industrial figures to this research:

Mr Andy Flower, a world renowned professional in global LNG trade, has been working as an independent consultant, in the sector, for the past 14 years. He retired from BP in 2001 after 32 years of service, including 22 years working in the company's LNG and natural gas unit where he managed BP's interests in a number of LNG projects. Mr Flower is a senior research fellow in the Oxford Institute for Energy Studies.

Mr Patrick Chaney is a senior marine engineer with 45 years of experience, 35 of it being in LNG sector. He is currently working on Magnolia LNG project. Previously he was the lead environmental and regulatory consultant to ExxonMobil in their Marine Well Containment Company $\backslash$ project (MWCC).

Ms Svetlana Androsova is a principal commercial adviser at QGC, a BG Group business. She has 20 years of experience in commercial shipping, the last 10 years of which has been with Russian, Qatari and Australian LNG projects.

Dr Steven Palmer, a marine professional of 28 -years experience, specializes primarily in the LNG sector where he has worked in several major LNG supply enterprises. Currently he is working for Qatar Gas Shipping Company, "Nakilat", as the Technical Manager for the fleet.

Mr Vilim Uzicanin is a chief engineer, working on the fleet of "K" Line LNG Shipping (UK). He has been at sea, serving on merchant vessels, for 24 years, with the past 16 years being in LNG sector.

* Primary parts of this work were carried out during Hamed Nikhalat-Jahromi's PhD studies, at Imperial College London. The final development was carried out by him, at INESC Porto, under the "NORTE-01-0145-FEDER-000020" project; this project was financed by the North Portugal Regional Operational Programme (NORTE 2020), under the Portugal 2020 Partnership Agreement, and through the European Regional Development Fund (ERDF).

\section{References}

1. ANDERSSON, H., HOFF, A., CHRISTIANSEN, M., HASLE, G. \& LøKKETANGEN, A. (2010a) Industrial Aspects and Literature Survey: Combined Inventory Management and Routing. Computers \& Operations Research, 37(9), 1515-1536.

2. ANDERSSON, H., CHRISTIANSEN, M. \& FAGERHOLT, K. (2010b) Transportation Planning and Inventory Management in the LNG Supply Chain. IN Bjørndal, E., Bjørndal, M., Pardalos, P. M. \& Rönnqvist, M. (Eds.) Energy, Natural Resources and Environmental Economics. Berlin, Springer, 429-441.

3. ANDROSOVA, SVETLANA. Principal Commercial Advisor at QGC, A BG Group Business. (Personal correspondence. 20 July 2015).

4. CHRISTIANSEN, M. \& FAGERHOLT, K. (2009) Maritime Inventory Routing Problems. IN FLOUDAS, C. A. \& PARDALOS, P. M. (Eds.) Encyclopedia of Optimization. 2nd Ed. New York (NY), Springer, 1947-1954. 
5. COELHO, L. C., CORDEAU, J., \& LAPORTE, G. (2013) Thirty Years of Inventory Routing. Transportation Science, 48(1): 1-19.

6. DAMODARAN, A. (2012) Investment Valuation: Tools and Techniques for Determining the Value of any Asset. 3rd Ed. New York, John Wiley \& Sons.

7. DELOITTE (2015) Middle East Tax Handbook 2015: Adapting to Regulatory Change. [Online] https://www2.deloitte.com/content/dam/Deloitte/xe/Documents/tax/me_tax_handbook_2 015.pdf, last retrieved at 31/07/2015.

8. DICKEL, R., GÖNÜL, G., GOULD, T., KANAI, M., KONOPLYANIK, A., SELIVANOVA, Y. \& JENSEN, J. (2007) Putting a Price on Energy: International Pricing Mechanisms for Oil and Gas. Brussels, Energy Charter Secretariat. [Online] http://www.encharter.org/fileadmin/user_upload/document/Oil_and_Gas_Pricing_2007_E NG.pdf, last retrieved at 31/07/2015.

9. FODSTAD, M., UGGEN, K. T., ROMO, F., LIUM, A., STREMERSCH, G. \& HECQ, S. (2010) LNG Scheduler: A Rich Model for Coordinating Vessel Routing, Inventories and Trade in the Liquefied Natural Gas Supply Chain. Journal of Energy Markets, 3(4): 31-64.

10. HARTLEY, P. R. (2013) The Future of Long-Term LNG Contracts. University of Western Australia Business School, discussion paper no. 13.22. [Online] http://www.business.uwa.edu.au/_data/assets/pdf_file/0009/2356524/13-22-The-Futureof-Long-term-LNG-Contracts.pdf, last retrieved at 31/07/2015.

11. HAWK, A., PACHECO-DE-ALMEIDA, G. \& YEUNG, B. (2013) Fast-Mover Advantages: Speed Capabilities and Entry into the Emerging Submarket of Atlantic Basin LNG. Strategic Management Journal, 34(13): 1531-1550.

12. IGU (International Gas Union). (2012) Natural Gas Conversion Pocketbook. [Online] http://agnatural.pt/documentos/ver/natural-gas-conversionpocketbook_fec0aeed1d2e6a84b27445ef096963a7eebab0a2.pdf, last retrieved at at $31 / 07 / 2015$.

13. IGU (2015) World LNG Report - 2015 Edition. [Online] http://igu.org/sites/default/files/node-page-field_file/IGU-World\%20LNG\%20Report2015\%20Edition.pdf, last retrieved at 31/07/2015.

14. JENSEN, J. T. (2004) The Development of a Global LNG Market: Is it Likely? If so, When? Oxford Institute for Energy Studies, NG 5. [Online] http://www.oxfordenergy.org/wpcms/wp-content/uploads/2010/11/NG5TheDevelopmentofAGlobalLNGMarketIsItLikelylfSoWhen-JamesJensen-2004.pdf, last retrieved at 31/07/2015.

15. LEE, H. (2005) Dawning of a New Era: The LNG Story. John F. Kennedy School of Government, Harvard University, working paper no. RWP05-053. [Online] http://papers.ssrn.com/sol3/papers.cfm?abstract_id=822356, last retrieved at 31/07/2015.

16. MICHOTFOSS, M. (2007) Introduction to LNG - an Overview on Liquefied Natural Gas (LNG), its Properties, Organization of the LNG Industry and Safety Considerations. Centre for Energy Economics, University of Texas. [Online] http://www.beg.utexas.edu/energyecon/Ing/documents/CEE_INTRODUCTION_TO_LNG_FIN AL.pdf, last retrieved at 31/07/2015. 
17. MONIZ, E. J., JACOBY, H. D. \& MEGGS, A. J. M. (2011) The Future of Natural Gas: An Interdisciplinary MIT Study. Massachusetts Institute of Technology. [Online] https://mitei.mit.edu/system/files/NaturalGas_Report.pdf, last retrieved at 31/07/2015.

18. NIKHALAT-JAHROMI, H., ANGELOUDIS, P., BELL, M.G.H. \& COCHRANE, R.A. (2015) Global LNG Trade: A Comprehensive and Up to Date Analysis. Maritime Economics \& Logistics, advance online publication October 8, doi: 10.1057/mel.2015.26.

19. OZELKAN, E. C., D'AMBROSIO, A. \& TENG, S. G. (2008) Optimizing Liquefied Natural Gas Terminal Design for Effective Supply-Chain Operations. International Journal of Production Economics, 111(2): 529-542.

20. RAKKE, J. G., STALHANE, M., MOE, C. R., CHRISTIANSEN, M., ANDERSSON, H., FAGERHOLT, K. \& NORSTAD, I. (2011) A Rolling Horizon Heuristic for Creating a Liquefied Natural Gas Annual Delivery Program. Transportation Research Part C: Emerging Technologies, 19(5), 896-911.

21. SEA RATES (2015) Distance \& Transit Time. [Online] https://www.searates.com/reference/portdistance/, last retrieved at 31/07/2015.

22. STOPFORD, M (2009) Maritime Economics.3rd Ed. London, Routledge.

23. WANG, H., RUTHERFORD, D. \& CHINMAY, D. (2014) Long-term Energy Efficiency Improvement for $L N G$ Carriers. The International Council on Clean Transportation, working paper 2014-8. [Online] http://www.theicct.org/sites/default/files/publications/ICCT_LNGcarriers_20140819.pdf, last retrieved at 31/07/2015.

24. ZHURAVLEVA, P. (2009) The Nature of LNG Arbitrage: An Analysis of the Main Barriers to the Growth of the Global LNG Arbitrage Market. Oxford Institute for Energy Studies, NG 31 [Online] http://www.oxfordenergy.org/wpcms/wp-content/uploads/2010/11/NG31TheNatureofLNGArbitrageAndAnAnalysisoftheMainBarriersfortheGrowthofGlobalLNGArbitr ageMarket-PolinaZhuravleva-2009.pdf, last retrieved at 31/07/2015. 


\section{Appendix A: supplementary material}

\section{A1. Reasons behind the choices and further detailed specifications for the LNG project}

\section{A1.1. Spot markets}

The prominent spot LNG importers in Asia and Europe, correspondingly, Japan and the UK are picked as potential spot markets for the project. Japan has been the backbone of LNG sector and is the biggest LNG consumer in the world. In the wake of the Fukushima nuclear crisis, it has increased its already dominant spot import, such that in 2014 it was the destination for more than $37 \%$ of the world LNG spot trade. The UK, with a considerable LNG storage capacity and a liquid gas market, is included as an option in any evaluation of LNG spot sale; in 2014, more than $90 \%$ of all the spot LNG sales destined for Europe ended in the UK (GIIGLN, 2015).

Note that the capacity of the maximum tanker that can be served at spot markets, just like the CIF/DES-LTC buyer's destinations, is $175,000 \mathrm{~m}^{3}\left(V_{d}\right)$.

\section{A1.2. Liquefaction plant}

In the tests performed, the expenses of liquefaction plant associated with the circulation of LNG in the tanks and re-liquefaction of its boil-off are not considered, as they are extremely small and negligible given the cheap prices of energy in Middle East.

The initial $\left(I^{0}\right)$ and minimum $(\underline{I})$ permitted inventory volumes in the liquefaction plant are, respectively, $50,000 \mathrm{~m}^{3}$ and $5,000 \mathrm{~m}^{3}$. No safety inventory volume is kept in this project $\left(\underline{I}=I^{M}\right)$; usually smaller liquefaction plants, due their low volume storage tanks, do not keep any safety inventory. The values used for the conversion from MMBtu to tonne $(L)$ and for the density (/), for the LNG produced in the plant, are, correspondingly, $0.0187 \mathrm{MMBtu} /$ tonnes and 0.45 tonnes/ m3, as usual (IGU, 2012a).

\section{A1.3. Shipping}

As discussed before, the LNG producer has 10 fixed tankers, none of which is considered dedicated to any specific LTC delivery. All the tankers are assumed to be available and ready for service at the beginning and during the study time period $\left[U_{h t}=1 . \forall, h \in H, t \in \widehat{T}(=T)\right]$. The size of these tankers is $165,000 \mathrm{~m}^{3}$ each, which is the size of the average LNG tanker in near future (Palmer, 2015).

The fixed tankers travel at an average speed of 19.5 knots (Bortnowska, 2010; Stanivuk and Tokic, 2013), therefore the return trip to the destinations defined for the LNG project in the South Korea, US, Japan and UK takes approximately, 26, 36, 28 and 28 days, respectively. Laden and ballast trips have equal lengths. In calculating the trip times, in addition to loading and discharging, that take one day each, queuing for and crossing the Suez Canal, on either way, is considered to take about one day too (Shea, 2015). Slow steaming in LNG sector is practiced when the fuel oil prices are high and the LNG prices are low. Yet, considering the low oil prices ahead resulting in low fuel oil prices (this is 
discussed later in Fuel costs), slow steaming is not economical and hence not considered as an option in this research.

Voyage costs for tankers:

Fuel costs: about half of the fuel a tanker burns in each day comes from fuel oil, while the remainder comes from the natural boil-off. The boil-off energy is sufficient for tankers in ports and in crossing the Suez Canal (Gilmore et al., 2005). Note that LNG tankers due to burning boil-off gas as part of their fuel are low emission compared to non-LNG vessels, e.g., container ships. For a discussion on the role of various technologies and policies in the reduction of greenhouse gas (GHG) emission in maritime transport sector, see, Vergara et al. (2012). Thomson et al. (2015) present an interesting assessment of the life-cycle emissions of natural gas, which is progressively burned as fuel in its LNG form in the seagoing vessels, compared to traditional petroleum-based fuels. LNG tankers burn IFO 380 with $3.50 \% \mathrm{~m} / \mathrm{m}$ (that is by weight) maximum sulphur content in the waters outside the emission control areas (ECAs). In crossing the ECAs, and in compliance with International Maritime Organization VIMO's MARPOL, Annex VI, regulation 14, in keeping their $S O_{x}$ and particulate matter emissions smaller-thanor-equal to $0.10 \% \mathrm{~m} / \mathrm{m}$, they have to burn a distillate fuel with a very low sulphur content. This fuel is typically marine gas oil (MGO) with $0.10 \% \mathrm{~m} / \mathrm{m}$ maximum sulphur. In addition to that, since 2020 onward, depending on the result of a review by 2018, subject to availability of the required fuel oil, regulation 14 obliges that ships' $S O_{x}$ and particulate matter emissions in all waters outside ECA to be smaller-than-or-equal to $0.50 \% \mathrm{~m} / \mathrm{m}$ (IMO, 2015). That means by then the LNG tankers have to replace IFO 380 with a new fuel oil with a lower sulphur content.

Given the competitive energy prices in Middle East, the tankers would, habitually, bunker at Fujairah (the bunker hub of Middle East), United Arab Emirates. Bunkering outside Middle East and on passage to the UK and Japan might occur due to poor planning resulting in running low on fuel oil, respectively, e.g., in Singapore and Gibraltar that offer prices roughly in the same range as Fujairah; but it is not common. Tankers do not make large deviations from their fixed service passage for bunkering, as it is not economical. For example, although Rotterdam fuel oil prices have historically been lower than Fujairah, tankers in delivering LNG cargoes to the UK do not steam up there for bunkering, as it is a large deviation.

For estimating the range of IFO 380's price in the LNG project over the next few years, the price of crude oil, West Texas Intermediate (WTI), is linked to the price of IFO 380 in Fujairah. The historical monthly prices of IFO 380 and crude oil WTI, over the past five years, are presented in Figure A1.1. 


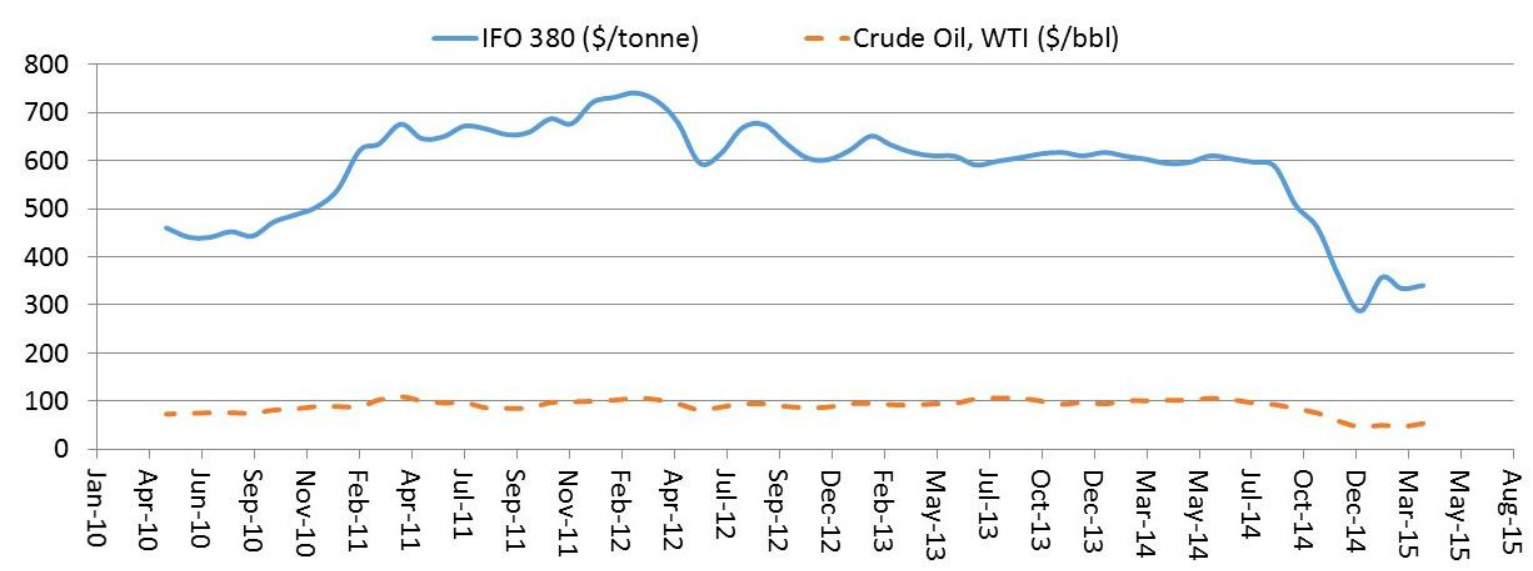

Figure A1.1 - History of monthly IFO 380 prices (\$/tonne) in Fujairah in comparison to crude oil, WTI [\$/oil barrel (bbl)], May 2010-April 2015 (source: Bunker Index, 2015; EIA, 2015).

As is clear from the above figure, following the recent substantial fall in oil prices, the IFO 380's price has also fallen. A correlation analysis shows a significant relationship between these two prices with the coefficient of determination $\left(r^{2}\right)$ being about $75 \%$. The regression equation for them is: IFO 380 price $(\$ /$ tonne $)=6.24 \times$ crude oil, $\mathrm{WTI}(\$ / \mathrm{bbl})+21.16$.

Market analysts (see, e.g.; Kaletsky, 2015) suggest that for the foreseeable future the Organization of the Petroleum Exporting Countries (OPEC) will attempt to cap the WTI oil prices at approximately $\$ 50 / \mathrm{bbl}$, which is the estimate for non-conventional oil production costs, to prevent any market share loss to non-conventional producers mainly based in North-America. The floor WTI price would be about $\$ 20 / \mathrm{bbl}$, which is the break-even point for conventional oilfields. However, the financial obligations of the producer countries may require a higher floor price. Therefore, the IFO 380 price, given its coherence with WTI, is expected to range between $\$ 146 /$ tonne and $\$ 333 /$ tonne. In the sensitivity tests, regarding the IFO 380's price, three scenarios are considered, as said before, the floor: \$146/tonne, the middle: $\$ 240 /$ tonne, and the cap: \$333/tonne.

The average tanker burns $0.12 \% /$ day of the LNG cargo, which naturally boils-off, in laden voyage, and $0.1 \% /$ day of the cargo in the ballast voyage. The cost of natural boil-off is the production expense of LNG at the liquefaction plant. Determining this expense, due to the reluctance of producers in disclosing commercially sensitive information, is difficult, however, it has been estimated to be approximately $\$ 1 / \mathrm{MMBtu}$ in the Middle East currently and for the near future (Flower, 2015). This is the production expense after recovery of CAPEX through depreciation, as the majority of LNG projects in the Middle East are mature (see; GIIGLN, 2015) and have passed their depreciation period. There is no prospect of new projects in Middle East at least in the short term, as, since a while back, rising domestic demand, lack of regulatory or energy policy clarity, absence of economic and political stability, and reserves which are more difficult to recover, have put any new investment in and development of the LNG projects in the region on halt (IGU, 2012b).

Canal charges: the Suez Canal fee in Subsection 3.1 is estimated to be $\$ 850,000$ for near future. There are very useful tools available online for calculating and estimating the Suez Canal fee, see, e.g., LETH 
Agencies (2015). The records of special drawing rights (SDR), which is the weighted currency basket based on which the canal fee is calculated, are available from IMF (2015).

\section{A1.4. LNG prices}

Figure A.1.2 shows the LNG spot prices (2009-2014) in the UK [the National Balancing Point (NBP) index - \$0.5/MMBtu; Flower, 2015] and Japan [the Japan Korea Marker (JKM) index measured by Platts]. The prices saw their biggest difference in 2012 , which was about $\$ 8 / \mathrm{MMBtu}$, as the result of Fukushima nuclear crisis. It is predicted that the restart of some Japanese nuclear power plants in 2015 (Oil Price, 2014), the slowing of the Chinese economy (Anderlini, 2014) in addition to two planned gas pipelines between China and Russia (Homeriki, 2014), and supply of LNG from new enterprises, particularly in Australia, that will increase the global liquefaction capacity $36 \%$ by 2018 , would shift the balance of global LNG trade to a buyer's market, at least for the next five years (Almeida, 2014), and result in a general decrease in prices worldwide. The decrease in prices is clear from early 2014 in Figure A1.2.

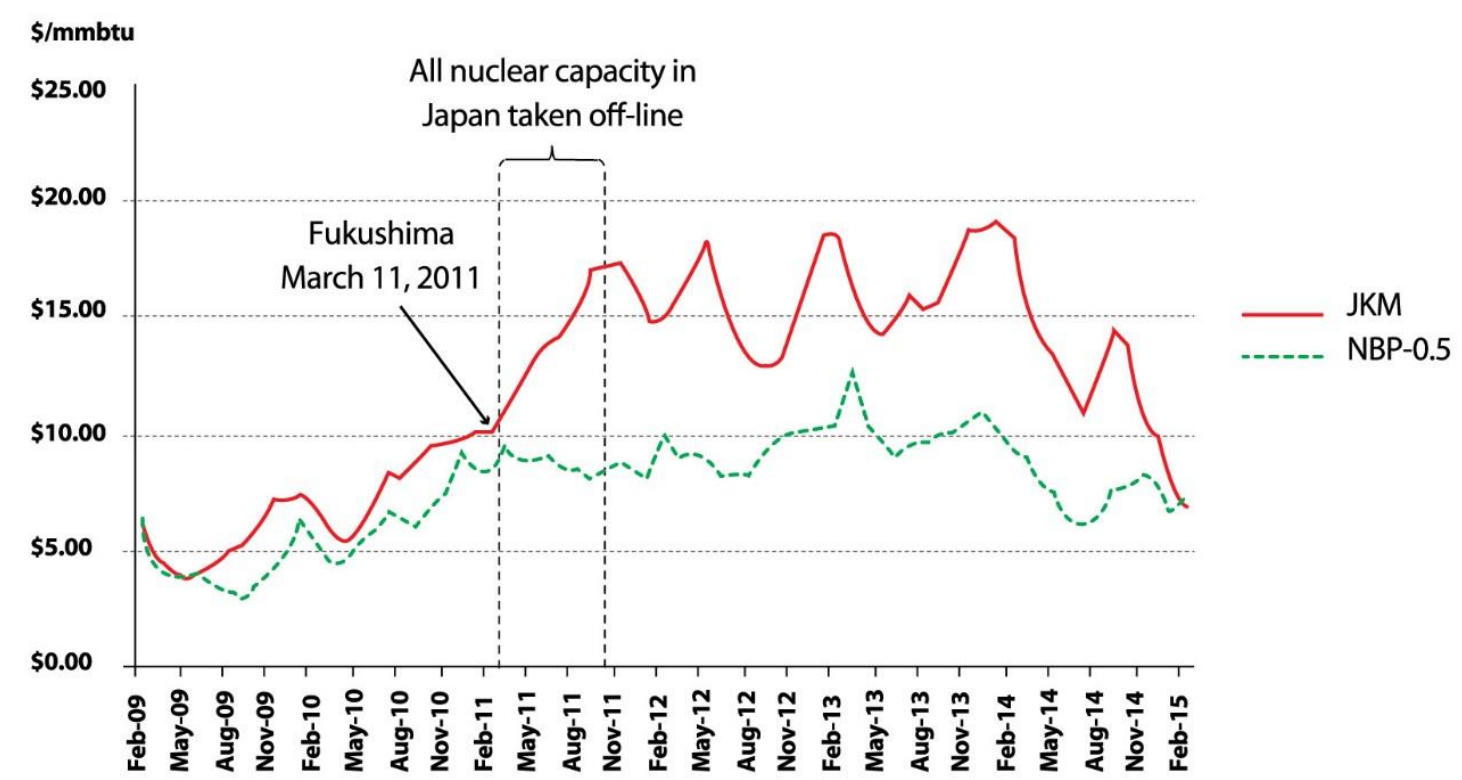

Figure A1.2 - LNG spot prices (\$/MMBtu) in the UK and Japan, 2009-2014 (adapted from: Johnson, 2015).

The degree to which prices and in particular the highly volatile spot prices will fall is very difficult to determine and a matter of speculation among analysts. Historically both the UK and Japanese spot prices experienced a record low in 2009, both approximately at $\$ 4 / \mathrm{MMBtu}$, at the height of the credit meltdown. For the sake of sensitivity tests this price is chosen as the floor and differences up to $\$ 8 / \mathrm{MMBtu}$ are considered between Japan and the UK. In this, nine scenarios of pairs of spot prices for Japan and the UK are considered (see, Table A1.1). 
Table A1.1 - Japan and UK LNG spot prices.

\begin{tabular}{cc}
\hline Price Scenario & (UK, Japan) prices (\$/MMBtu) \\
\hline A & $(12,4)$ \\
B & $(10,4)$ \\
C & $(8,4)$ \\
D & $(6,4)$ \\
E & $(4,4)$ \\
F & $(4,6)$ \\
G & $(4,8)$ \\
H & $(4,10)$ \\
I & $(4,12)$ \\
\hline
\end{tabular}

The authors are aware that Japanese LNG prices are, in general, higher than the UK prices; as Japan is highly dependent on gas as an energy source, with LNG being the major source of gas, which provides leverage for LNG producers in pricing their export to Japan. Yet a shift to an LNG buyer's market, coupled with a surge in Australian LNG supply from sources closer to Japan, could change this dynamic. So scenarios A, B, C, and D in Table A1.1, although less likely than the others, should not be branded as infeasible. 


\section{A2. Detail of results}

Tables A2.1-A2.3 present the results for spot sale of uncommitted LNG from Middle East to Japan/UK, for the floor (\$146/tonne), middle (\$240/tonne), and cap (\$333/tonne) prices of IFO 380, considering the LNG spot price scenarios presented in Table A1.1. In all the tables, somewhere between LNG price scenarios $D$ and $E$ the market of choice changes. Note that all the sensitivity tests in this research are carried out on a computer with $3.50 \mathrm{GHz}$ AMD-FX(tm)-8320 Eight-Core Processor and 16 GB RAM. The branch-and-bound node limit in the optimizer, ILOG CPLEX Optimization Studio 12.6.1, for the tests is set to 500,000, while the other settings are left with the default values.

Table A2.1 - Results for IFO 380's floor price scenario in choosing the appropriate spot market between Japan and the UK*.

\begin{tabular}{cccc}
\hline $\begin{array}{c}\text { Japan and UK LNG spot price } \\
\text { scenario }\end{array}$ & $\begin{array}{c}\text { Objective function value }(\$ \\
\text { millions) }\end{array}$ & $\begin{array}{c}\text { Computation time } \\
\text { (seconds) }\end{array}$ & $\begin{array}{c}\text { Spot market of } \\
\text { choice }\end{array}$ \\
\hline A & 25.105 & 16.84 & UK \\
B & 17.102 & 17.06 & UK \\
C & 9.100 & 16.58 & UK \\
D & 1.097 & 16.75 & UK \\
E & -6.076 & 16.69 & Japan \\
F & 1.927 & 17.28 & Japan \\
G & 9.929 & 16.73 & Japan \\
H & 17.932 & 16.52 & Japan \\
I & 25.934 & 16.64 & Japan \\
\hline
\end{tabular}

* The number of continuous and binary variables for each test is 6,301 and 20,465, respectively, while the number of constraints is 51,189 . The computation time and statistics on number of variables and constraints are not presented for the rest of tests in this research, suffice to say they are in the same order of magnitude as those reported in this table.

Table A2.2 - Results for IFO 380's middle price scenario in choosing the appropriate spot market.

\begin{tabular}{ccc}
\hline spot price scenario & Objective function value (\$ millions) & Spot market of choice \\
\hline A & 21.408 & UK \\
B & 13.405 & UK \\
C & 5.403 & UK \\
D & -2.600 & UK \\
E & -9.786 & Japan \\
F & -1.784 & Japan \\
G & 6.219 & Japan \\
H & 14.221 & Japan \\
I & 22.224 & Japan \\
\hline
\end{tabular}


Table A2.3 - Results for IFO 380's cap price scenario in choosing the appropriate spot market.

\begin{tabular}{ccc}
\hline spot price scenario & Objective function value (\$ millions) & Spot market of choice \\
\hline A & 17.750 & UK \\
B & 9.748 & UK \\
C & 1.745 & UK \\
D & -6.257 & UK \\
E & -13.457 & Japan \\
F & -5.455 & Japan \\
G & 2.548 & Japan \\
H & 10.550 & Japan \\
I & 18.553 & Japan \\
\hline
\end{tabular}

The details of results for further sensitivity tests when the LNG spot prices of Japan and the UK are equal, ranging between $\$ 5 / \mathrm{MMBtu}$ and $\$ 12 / \mathrm{MMBtu}$, are presented in Table A2.4. The tests show that the choice, for sale of uncommitted Middle Eastern LNG, between Japan and the UK is insensitive to the IFO 380 price. In other words, in picking between these two destinations, the market with higher spot price should be chosen.

Table A2.4 - Comparison of objective function values (\$ millions) for unforced and forced spot sale with LNG spot prices ranging between $\$ 5 / \mathrm{MMBtu}$ and $\$ 12 / \mathrm{MMBtu} *$.

\begin{tabular}{|c|c|c|c|c|c|}
\hline \multirow[t]{2}{*}{ Item } & \multicolumn{2}{|c|}{$\begin{array}{c}\text { Japan and the UK LNG spot } \\
\text { price }\end{array}$} & \multirow{2}{*}{$\begin{array}{l}\text { Floor price for } \\
\text { IFO } 380\end{array}$} & \multirow{2}{*}{$\begin{array}{l}\text { Middle price for } \\
\text { IFO } 380\end{array}$} & \multirow{2}{*}{$\begin{array}{l}\text { Cap price for } \\
\text { IFO } 380\end{array}$} \\
\hline & Scenario & Price (\$/MMBtu) & & & \\
\hline Unforced & \multirow{3}{*}{$\mathrm{J}$} & \multirow{3}{*}{5} & -2.112 & -5.823 & -9.494 \\
\hline Forced & & & -2.941 & -6.638 & -10.296 \\
\hline Difference in sales & & & 0.829 & 0.816 & 0.803 \\
\hline Unforced & \multirow{3}{*}{$\mathrm{K}$} & \multirow{3}{*}{6} & 1.927 & -1.784 & -5.530 \\
\hline Forced & & & 1.097 & -2.600 & -6.332 \\
\hline Difference in sales & & & 0.829 & 0.816 & 0.803 \\
\hline Unforced & \multirow{3}{*}{$\mathrm{L}$} & \multirow{3}{*}{7} & 5.890 & 2.180 & -1.491 \\
\hline Forced & & & 5.061 & 1.364 & -2.294 \\
\hline Difference in sales & & & 0.829 & 0.816 & 0.803 \\
\hline Unforced & \multirow{3}{*}{ M } & \multirow{3}{*}{8} & 9.929 & 6.219 & 2.548 \\
\hline Forced & & & 9.100 & 5.403 & 1.745 \\
\hline Difference in sales & & & 0.829 & 0.816 & 0.803 \\
\hline Unforced & \multirow{3}{*}{$\mathrm{N}$} & \multirow{3}{*}{9} & 13.893 & 10.182 & 6.512 \\
\hline Forced & & & 13.064 & 9.367 & 5.709 \\
\hline Difference in sales & & & 0.829 & 0.816 & 0.803 \\
\hline Unforced & \multirow{3}{*}{0} & \multirow{3}{*}{10} & 17.932 & 14.221 & 10.550 \\
\hline Forced & & & 17.102 & 13.405 & 9.748 \\
\hline Difference in sales & & & 0.829 & 0.816 & 0.803 \\
\hline Unforced & \multirow{3}{*}{$\mathrm{P}$} & \multirow{3}{*}{11} & 21.895 & 18.185 & 14.514 \\
\hline Forced & & & 21.066 & 17.369 & 13.712 \\
\hline Difference in sales & & & 0.829 & 0.816 & 0.803 \\
\hline Unforced & \multirow{3}{*}{$Q$} & \multirow{3}{*}{12} & 25.934 & 22.224 & 18.553 \\
\hline Forced & & & 25.105 & 21.408 & 17.750 \\
\hline Difference in sales & & & 0.829 & 0.816 & 0.803 \\
\hline
\end{tabular}

* In unforced sale for all the cases the market of choice is Japan, hence the market in forced sale is always the UK. 


\section{References}

1. ALMEIDA, I. (2014) BofA Sees Global LNG Entering Multiyear Bear Market on Supplies. [Online] http://www.bloomberg.com/news/2014-12-09/bofa-sees-global-Ing-enteringmultiyear-bear-market-on-supplies.html, last retrieved at 31/07/2015.

2. ANDERLINI, J. (2014) China's Growth in Danger of Slowing More Sharply. [Online] http://www.ft.com/cms/s/0/ccb72910-60f1-11e4-894b-00144feabdc0.html, last retrieved at $31 / 07 / 2015$.

3. BORTNOWSKA, M. (2010) Technological and Operational Concept of an LNG Carrier. Scientific Journals of Maritime University of Szczecin, 21(93): 28-33.

4. BUNKER INDEX (2015) Fujairah, United Arab Emirates: Daily Port Prices. [Online] http://www.bunkerindex.com/prices/portfree_xmdo.php?port_id=214, last retrieved at $31 / 07 / 2015$.

5. EIA (Energy Information Administration). (2015) Spot Prices. [Online] http://www.eia.gov/dnav/pet/pet_pri_spt_s1_m.htm, last retrieved at 31/07/2015.

6. FLOWER, ANDY. LNG Consultant. (Personal correspondence. 27 July 2015).

7. GIIGNL (Groupe International des Importateurs de Gaz Natural). (2015) The LNG Industry in 2014. [Online] http://www.giignl.org/sites/default/files/PUBLIC_AREA/Publications/giignl_2015_annual_re port.pdf, last retrieved at 31/07/2015.

8. GILMORE, R., HATZIGRIGORIS, S., MAVRAKIS, S., SPERTOS, A., \& VORDONIS, A. (2005). LNG Carrier Alternative Propulsion systems. Technical report, SNAME GREEK SECTION. [Online] http://www.scribd.com/doc/222599621/Lng-Carrier-Alternative-Propulsion-Systems\#scribd, last retrieved at 31/07/2015.

9. HOMERIKI, L. (2014) Russia to Build Second Gas Pipeline to China after Beijing Agreement. [Online] http://rbth.co.uk/business/2014/11/13/russia_to_build_second_gas_pipeline_to_china_aft er_beijing_agreement_41393.html, last retrieved at 31/07/2015.

10. IGU (International Gas Union). (2012a) Natural Gas Conversion Pocketbook. [Online] http://agnatural.pt/documentos/ver/natural-gas-conversionpocketbook_fec0aeed1d2e6a84b27445ef096963a7eebab0a2.pdf, last retrieved at at $31 / 07 / 2015$.

11. IGU (2012b) World LNG Report 2011. [Online] http://www.igu.org/sites/default/files/nodepage-field_file/LNG\%20Report\%202011.pdf, last retrieved at 31/07/2015. 
12. IMF (International Monterey Fund). (2015) Exchange Rate Query Tool. [Online] https://www.imf.org/external/np/fin/ert/GUI/Pages/CountryDataBase.aspx, last retrieved at 31/07/2015.

13. IMO (International Maritime Organization). (2015) Sulphur oxides (SOx) - Regulation 14.

[Online]

http://www.imo.org/en/OurWork/Environment/PollutionPrevention/AirPollution/Pages/Sul phur-oxides-(SOx)-\%E2\%80\%93-Regulation-14.aspx, last retrieved at 31/07/2015.

14. JOHNSON, T. (2015) LNG Exports from Canada a Distant Prospect, Analyst Says. CBC News. [Online] http://www.cbc.ca/news/business/Ing-exports-from-canada-a-distant-prospectanalyst-says-1.2978953, last retrieved at 31/07/2015.

15. KALETSKY, A. (2015) A New Ceiling for Oil Prices. Project Syndicate. [Online] http://www.project-syndicate.org/commentary/oil-prices-ceiling-and-floor-by-anatolekaletsky-2015-01, last retrieved at 31/07/2015.

16. LETH AGENCIES (2015) Tariff 2014. [Online] http://lethagencies.com/egypt/canal-tariffegypt/tariff-2014, last retrieved at 31/07/2015.

17. OIL PRICE (2014) Will Low Oil Prices Shatter LNG Hopes? [Online] http://oilprice.com/Energy/Natural-Gas/Will-Low-Oil-Prices-Shatter-LNG-Hopes.html, last retrieved at 31/07/2015.

18. PALMER, STEVEN. Technical Manager at Qatar Gas Transport Company (NAKILAT). (Personal correspondence. 26 July 2015).

19. SHEA, D. (2015) The New Suez Canal: Racing Against Time. [Online] https://www.onboardonline.com/industry-article-index/shipping/the-new-suez-canalracing-against-time/, last retrieved at 31/07/2015.

20. STANIVUK, T. \& TOKIC, T. (2013) Alternative Shipping Routes and Simulations of LNG Storage at Export/Import Terminals. Journal of Marine Sciences, 60(3-4): 61-67.

21. THOMSON, H., CORBETT, J. J. \& WINEBRAKE, J. J. (2015) Natural Gas as a Marine Fuel. Journal of Energy Policy, 87: 153-167.

22. VERGARA, J., MCKESSON, C. \& WALCZAK, M. (2012) Sustainable Energy for the Marine Sector. Journal of Energy Policy, 49: 333-345. 